\title{
TO EVALUATE THE UTILIZATION OF LIVER FUNCTION TESTS IN HOSPITALIZED PATIENTS.
}

1. M.Phil. Chemical Pathology Assistant Professor

Department Pathology

King Edward Medical University

2. MBBS

Demonstrator

Department of Pathology

King Edward Medical University

3. MLT

King Edward Medical University

Correspondence Address:

Dr. Nida Iqbal

34-Fasial block Azam Garden,

Lahore.

aquario_2@live.com

Article received on:

10/11/2018

Accepted for publication:

$15 / 02 / 2019$

Received after proof reading:

$31 / 07 / 2019$

\begin{abstract}
Rehma Dar', Nida Iqbal ${ }^{2}$, Ayesha Ashfaq ${ }^{3}$
ABSTRACT... Laboratory testing plays an important part in Clinical decisions. $60-70 \%$ of the clinical decisions are based on laboratory tests. The volume of laboratory tests has increased in last few years that results inappropriate utilization for routine tests. The elimination of unnecessary tests will help to utilize time and resources more effectively. To study the utilization of Liver functions tests (LFTs) in hospitalized patients of Mayo Hospital in 10 days. Study Design: Observational Study. Setting: Central Diagnostic Laboratory, Mayo Hospital/ King Edward Medical University, Lahore. Period: $1^{\text {st }}$ to $10^{\text {th }}$ December, 2017. Materials and Methods: All the samples from indoor patients referred to laboratory for LFTs were included. The results and other relevant information were recorded on Proforma. The collected data was analyzed by using Statistical package for social sciences (SPSS version 20). Results: Out of total 1800 samples referred for LFTs, $1500(83.4 \%)$ were accepted and $300(16.6 \%)$ were rejected due to inappropriate sample (hemolysis, quantity not sufficient, empty vial, EDTA vial, labeling error). The results of LFTs of $59 \%$ samples were within reference range and $41 \%$ were out of range. $23.5 \%$ samples were repetitive and $8.6 \%$ reports were not collected by the wards either the patient was discharged from the hospital or due to repetitive sampling. Conclusion: There is overutilization of Liver function tests. The repetitive ordering and inappropriate samples are main reason of waste in our study.
\end{abstract}

Key words: $\quad$ Clinical decisions, General Biochemistry, LFTs, Laboratory Utilization.

Article Citation: Dar R, Iqbal N, Ashfaq A. To evaluate the utilization of liver function tests in hospitalized patients. Professional Med J 2019; 26(8):1222-1228. DOI: 10.29309/TPMJ/2019.26.08.723

\section{INTRODUCTION}

Laboratory testing is an important part of Clinical decisions. Laboratory tests help not only in diagnosis but also aid in screening, prognosis and management of disease. $60-70 \%$ of the most important decisions on admission, discharge and medication are based on laboratory test results. ${ }^{1}$

Laboratory testing is one of the largest volume activities of health system. The studies indicate a 17 -fold increase in the number of tests ordered by health care providers since 1973. The increased volume of laboratory testing has resulted in inappropriate utilization of laboratory tests ranging from $11 \%$ to $70 \%$ for general biochemistry and hematology tests. ${ }^{2}$

This inappropriate utilization includes both overutilization and underutilization of laboratory services. A study by McConnell $\mathrm{T}$ et al documented $26.5 \%$ and $42.8 \%$ unnecessary laboratory tests identified by pathologists and physicians respectively. Overall $29-56 \%$ of all the laboratory tests are over utilized globally. Routine Clinical Chemistry tests are among the top ten over utilized tests. ${ }^{3}$

There are many underlying reasons for overutilization of laboratory services like automated laboratory technologies, lack of evidence based recommendations for ordering tests, a comprehensive list of tests available in laboratory test menu, lack of laboratory medicine training in Medical schools and over bundling of test panels that make easier for clinicians to order more tests. In addition, the laboratories do not have a test utilization review process in place to cut down the testing choices. ${ }^{4}$ 
The healthcare budgets worldwide are facing increasing pressure to reduce costs and improve quality and efficiency. Although the diagnostic laboratories account for only $4 \%$ of hospital budget, they are often targeted primarily to control health expenditure. Since the significant percentage of laboratory tests are unnecessary, the impact on overall cost of health care is substantial. ${ }^{5,2}$

The elimination of unnecessary tests will help to spare time to be utilized in more important duties like STAT testing on critically ill patients that will help to reduce turnaround time and help in their effective management. In addition, time and burden on the hospital staff to collect blood specimens will be reduced. Moreover, the repetitive blood drawing increases risk of hospital-acquired anemia (HAA) in patients. The resources saved from unnecessary tests can be reallocated to important test that are underutilized like lipids screening, glycemic control indicators and infectious diseases screening. ${ }^{6}$

The Utilization management has been a traditional approach to control costs in health-care systems. Utilization management is defined as "Evaluation of the necessity, appropriateness, and efficiency of the use of health care services, procedures and facilities." The clinical laboratories are often focused for controlling health expenses in addition to pharmacy and radiology. These services are targeted because they are generally perceived to be over utilized (or miss-utilized) and because they are readily quantifiable. Volume and unit cost data can be easily obtained to estimate the savings resulting from individual utilization management initiatives. ${ }^{7}$

The role of Utilization management is more important in indoor patients as they pay once to the hospital at the time of admission regardless of number of investigations ordered for them. There is a demand to reduce inpatient testing as excess tests incur additional costs to hospital without generating any revenue. On the other hand, outpatient testing is generally on payment and less frequent. The more tests that are performed, the more revenue is generated. ${ }^{8}$
The efficient managing laboratory test utilization requires both ensuring adequate utilization of needed tests in some patients and discouraging superfluous tests in other patients. Utilization management is the responsibility of both laboratory staff and clinicians. They should review the laboratory data and formulate guidelines to reduce waste and effectively utilize the available resources. $^{9}$

To sum up it is to do the right test on the right patient at the right time and to do it accurately. Since the laboratory results are very important in patient care decisions, the appropriate tests ordered with accurate results ensure proper downstream patient care. However, inappropriate tests results in unnecessary and costly downstream activities. ${ }^{10}$

The monitoring of laboratory utilization will have good impact on healthcare services. It will conserve resources by reducing unnecessary testing and utilize the conserved resources on other aspects of better patient care. ${ }^{11}$

Management is the responsibility of both laboratory staff and clinicians. They should review the laboratory data and formulate guidelines to reduce waste and effectively utilize the available resources. ${ }^{12}$

In this background, this study was planned to estimate the utilization of Liver function tests in hospitalized (indoor) patients in Central Diagnostic Laboratory of Mayo Hospital/ King Edward Medical University in 10 days.

\section{METHODOLOGY}

\section{Ethical Issue}

The study design was approved by the Institutional Review Board.

\section{Study Design}

Observational Study.

\section{Study Setting}

Study was conducted at Central Diagnostic Laboratory, Mayo Hospital/ King Edward Medical 
University, Lahore the Pathology laboratory of King Edward Medical University.

\section{Sample Size}

All the samples from indoor patients from $1^{\text {st }}$ to $10^{\text {th }}$ December, 2017 referred to laboratory for LFTs were included. The results of LFTs and other relevant information of hospitalized patients were noted on Proforma. Any information that could result in repeat sample like hemolysis, inadequate sample or wrong sample was being noted. The result of each sample was marked as normal or abnormal.

\section{Statistical Analysis}

All collected data was entered and analyzed by using Statistical package for social sciences (SPSS version 20). Quantitative variables like age was presented as mean \pm SD. Qualitative variables like gender, clinical specialty, normal or abnormal LFTs reports, hemolysis, inadequate sample or wrong sample type was presented as frequency and percentage.

\section{RESULTS}

\begin{tabular}{|l|c|}
\hline \multicolumn{1}{|c|}{ Study Variables } & Mean/ $\%$ \\
\hline Age & $42.2+14.3$ years \\
\hline Gender(M:F) & $47 \%: 53 \%$ \\
\hline Total samples & 1800 \\
\hline Accepted/ Rejected & $1500(83 \%) / 300(17 \%)$ \\
\hline Normal/Abnormal & Medicine $17 \%$, Surgical $43 \%$, \\
Oncology $32 \%$, ICU $8 \%$
\end{tabular}

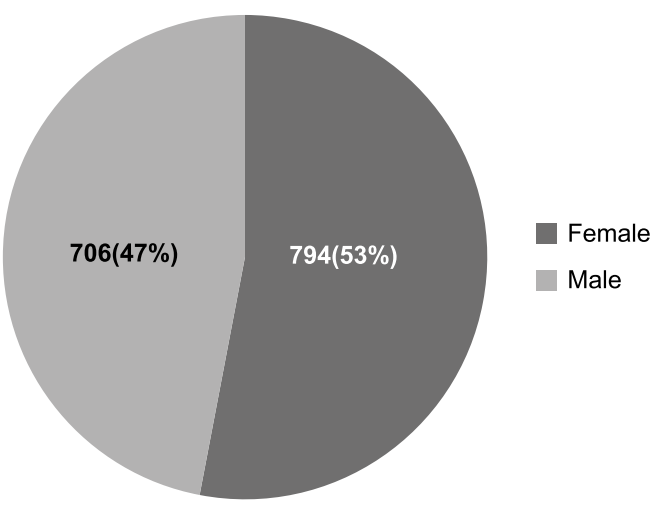

Figure-1. Percentage of Male and Female patients

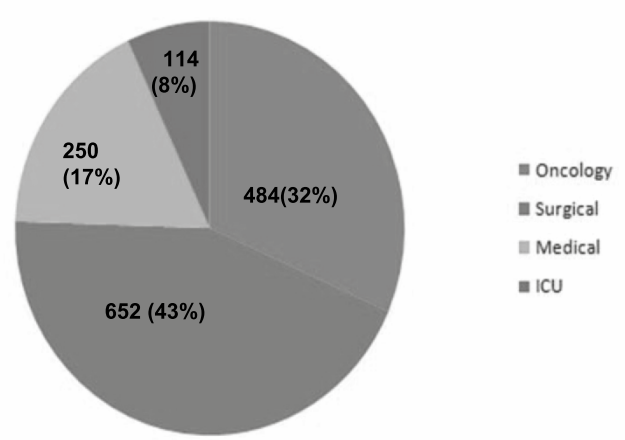

Figure-2. Number of patients from different wards

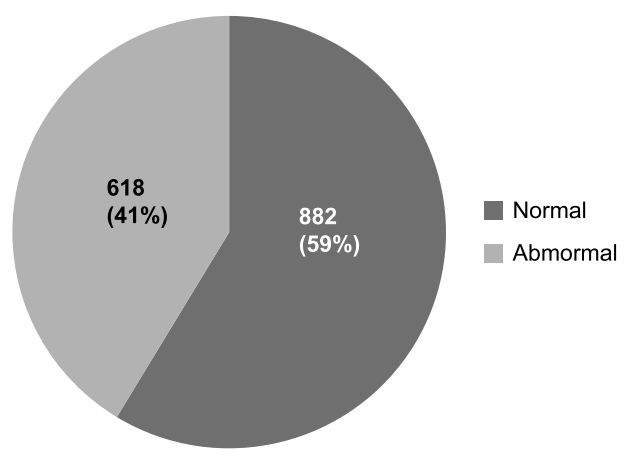

Figure-3. Frequency of Normal and Abnormal test

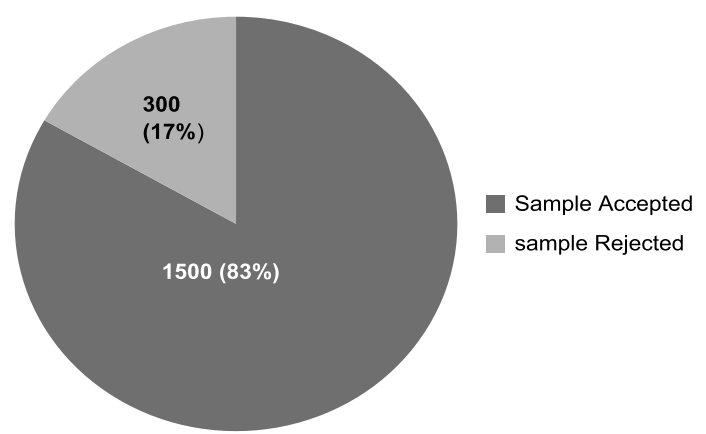

Figure-4. Accepted and Rejected samples

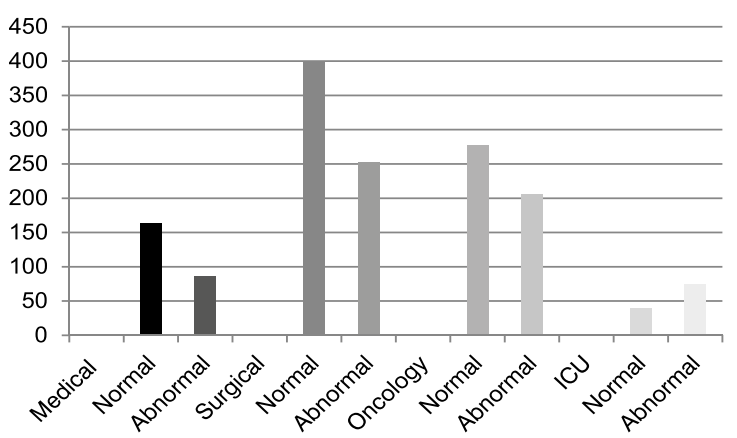

Figure-5. Frequency of Normal and Abnormal tests in different wards 


\section{DISCUSSION}

Laboratory tests have a very important role in clinical practice. They help clinicians not only in diagnosis but also aid in assessing effectiveness, compliance and complications of treatment.

Laboratory testing is the highest volume activity of healthcare system. ${ }^{13}$

It increases the overall cost of health care. The inappropriate utilization of laboratory services, in addition to financial burden results in other substantial effects like iatrogenic blood loss, follow-up testing and prolonged hospital stay. ${ }^{14}$

Inappropriate utilization of laboratory services includes both underutilization and overutilization. Underutilization means clinically indicated tests are nor ordered while overutilization is frequent ordering of test. ${ }^{15,16,17,18}$

Utilization of laboratory testing is of great concern due to increasing volume and budget of laboratory services. In this background, this study was planned to analyze the utilization of one of the routine Clinical chemistry tests - Liver function tests (LFTs) in hospitalized patients.

LFTs were ordered on 1800 samples out of which 300 (16.6\%) samples were rejected due to inappropriate sample (hemolysis, quantity not sufficient, empty vial, EDTA vial, labeling error) (Table-I) $1500 \quad$ (83.4\%) samples were accepted(Figure-4). The results of LFTs of $59 \%$ samples were within reference range and $41 \%$ were out (Figure-3). The distribution of normal and abnormal results in all specialties were same (57-66\% normal and 34-43\% abnormal) except ICUs. There were $65 \%$ abnormal and $35 \%$ normal results in ICUs. (Figure-3 \& 5) 23.5\% samples were repetitive and $8.6 \%$ reports were not collected by the wards either the patient was discharged from the hospital or repetitive sampling. (Table-I)

The results of our study show overutilization of LFTs- a common Clinical chemistry test. This not only added financial burden and workload to the laboratory but also resulted in waste of hospital resources in terms of time and labor (time taken to fill in request forms, draw samples, to deliver samples and to collect reports).

The results of our study are supported by Lew and rowskik et al. and Malthen $D$ et al. who concluded LFTs as one of the most over utilized tests. A thorough meta-analysis also supports our study. ${ }^{19,20,15}$

Our study results are also in accordance with the one carried out at Beth Israel Deaconess Medical Center (BIDMC). They analyzed more than 1.6 million laboratory results for the most commonly ordered tests and found that nearly one-third of all laboratory testing was unnecessary. ${ }^{21,15}$

The waste of laboratory services is mainly in terms of overutilization that involves too much repeated testing. This is particularly for indoor patients through standing orders that are convenient to place. The prolonged laboratory turnaround time (TAT) also contributes to repetitive testing. ${ }^{9}$

In addition to repeated testing, inappropriate samples (hemolysis, quantity not sufficient, empty vials, EDTA vial, and labeling error) also contribute to waste.

A study undertaken in San Francisco Medical Center showed that majority of tests being ordered did not have a significant impact on patient care. The patient care was not affected by $50 \%$ reduction in five common laboratory tests. ${ }^{15,22}$

One of the reasons behind misuse of laboratory service is the way the test menu is presented whether through computerized system or paper requisition. It influences the selection of clinician. The frequency of test ordering is more for predefined test menus than opt-out method. ${ }^{23}$

Cutting down unnecessary testing not only helps to lessen financial burden but also improves turnaround time for critically ill patients. This also spares time and staff from blood collection to be utilized for patient care. ${ }^{24}$

Strategies need to be formulated to manage 
the proper utilization of laboratory services. Lab personnel's must work in collaboration with clinicians to develop practical guidelines for different tests. Frequency must be defined to limit repetitive sampling. Continuous training and education of staff involved in blood sampling is needed to decrease waste by producing appropriate samples.

A comprehensive Laboratory Information System needs to be installed to mange laboratory utilization. The duplicate samples must be identified by the system and its entry should be blocked unless valid reason is added to repeat. The tests under processing to generate results should be highlighted to physician. ${ }^{25}$

Audits need to be conducted both at hospital and laboratory end to review the ordering of existing tests and to add new tests. After audits, the changes implemented in practices both at laboratory and clinician end must be assessed by their clinical impact on patients. ${ }^{26}$

\section{CONCLUSION}

There is overutilization of Liver function tests. The repetitive ordering and inappropriate samples are main reason of waste in our study.

\section{RECOMMENDATIONS}

There is a need of LIS to prevent overutilization of laboratory tests. The software should have features to add reasoning/ provisional diagnosis to order laboratory tests and to prevent repetitive ordering within short time frame without adding a valid reason for it.

The audits of in house available laboratory tests must be encouraged by clinicians. It will help to cut down unnecessary laboratory tests to make room for adding more useful tests for better patient care within allocated budget.

\section{LIMITATIONS}

The collection of data was done manually by reviewing patients' requisition forms and their reports due to lack of LIS. The poor documentation in terms of clinical diagnosis and illegible handwriting blurred the research findings. As the reports are dispatched manually, the delay at some point might result in repetitive sampling that is difficult to pin point without LIS.

\section{CONFLICT OF INTEREST}

No conflict of interest.

Copyright $@ 15$ Feb, 2019.

\section{REFERENCES}

1. Datta P. Resolving discordant specimens. ADVANCE for Administrators of the Laboratory. 2005 Jul;60.

2. Pageler NM, Franzon D, Longhurst CA, Wood M, Shin AY, Adams ES, et al. Embedding time limited laboratory orders within computerized provider order entry reduces laboratory utilization. Pediatr Crit Care Med 2013; 14:413-19.

3. McConnell T, Berger P, Dayton H, Umland B, Skipper B. Professional review of laboratory utilization. Human Pathol.1982; 13:399-403.

4. Bishop ML, Fody EP, Schoeff LE. Clinical chemistry: techniques, principles, correlations/ [edited by] Michael L. Bishop, Edward P. Fody, Larry E. Schoeff. Philadelphia: Wolters Kluwer Health/Lippincott Williams \& Wilkins,; 2010.

5. Fryer AA, Smellie WS. Managing demand for laboratory tests: A laboratory toolkit. J Clin Pathol 2013; 66:62-72.

6. Salisbury A, Alexander K, Reid K, Masoudi F, Rathore S, etal. Incidence, correlates, and outcomes of acute, hospital acquired anemia in patients with myocardial infarction. Circ Cardiovasc Qual Outcomes. 2010; 3:337-46.

7. Academy Health. Glossary of terms commonly used in healthcare. Washington; 2004. Available from:http:// www.academyhealth.org/files/publications/glossary. pdf.

8. Gowda S, Desai P, Hull V, Math A, NVernekar S, Kulkarni S. A review on laboratory liver function tests 2009 . $17 p$.

9. Baird $\mathrm{G}$. The laboratory test utilization management tool box. Biochemiamedica: Biochemiamedica. 2014; 24(2):223-34.

10. Sandler G. Do emergency tests help in the management of acute medical admissions? BrMedJ (Clin Res Ed) 1984; 289:973-7.

11. KwokJ, Jones B. Unnecessary repeat requesting of tests: An audit in a government hospital immunology laboratory. J Clin Pathol 2005; 58:457-62. 
12. Grumet G. Health care rationing through inconvenience. NEJM. 1989; 321:607-11.

13. National physicians alliance promoting good stewardship in medicine. http://npalliance.org/ promoting-good-stewardship-inmedicine-project/. Accessed 23 Mar 2015.

14. Kim Futrell MAM. Effective Test Utiliztion. [Online]. Available from: https://www.google.com.pk/ search? source $=h p \& q=$ Effective + Test + Utilization\%3A+A+Laboratory\%[Accessed 09 Sept. 2017].

15. Krasowski MD, Chudzik D, Dolezal A, Steussy B, Gailey MP, Koch B, etal. Promoting improved utilization of laboratory testing through changes in an electronic medical record: Experience at an academic medical center. BMC medical informatics and decision making. 2015; 15(1):11.

16. Zhi M, Ding EL, Theisen-Toupal J, Whelan J, Arnaout $R$. The landscape of inappropriate laboratory testing: A 15-year meta-analysis. PLoS One 2013; 8:e78962. http://dx.doi. org/10.1371/journal. pone.0078962.

17. Holland LL, Smith LL, Blick KE. Reducing laboratory turnaround time outliers can reduce emergency department patient length of stay: An 11-hospital study. Am J Clin Pathol 2005; 124:672-4.

18. Roberts R. A customized genetic approach to the number one killer: Coronary phttp://dx.doi. org/10.1097/HCO.0b013e32830e6b4e.

19. Lewandrowski K, BaronJ, Dighe A. Utilization management in the clinical laboratory: An introduction and overview. Utilization management in the clinical laboratory and other ancillary services: Springer; 2017.p.7-29.
20. Shannon CE. Communication in the presence of noise. Proc IRE. 1949; 37:1021. doi:10.1109/. JRPROC.1949.232969.

21. National physicians alliance promoting good stewardship in medicine. http://npalliance.org/ promoting-good-stewardship-inmedicine-project/. Accessed 23 Mar 2015.

22. Meidani Z, Farzandipour M, Farrokhian A, Haghighat $M$. A review on laboratory tests'utilization:A trigger for cutting costs and quality improvement in health care settings. Medical Journal of the Islamic Republic of Iran. 2016; 30:365-.

23. Kim Futrell MAM. Effective test utilization. [Online]. Availablefrom:https://www.google.com.pk/ search? source $=$ hp \& $q=$ Effective + Test + Utilization\%3A+A+Laboratory\%[Accessed09 Sept.2017]

24. Ming Zhi, Eric L. et. al. "The landscape of inappropriate laboratory testing: A 15-year meta-analysis." PLOS|One. November 2013. Accessed at: www. plosone.org/article/info\%3Adoi\%2F10.1371\%2Fjournal. pone.0078962.

25. Zhao J, Liberman A. Pathologist's role in clinical utilization management: A financing model for managed care. Am J ClinPathol. 2000; 113:336-42.

26. Smellie WS. Demand management and test request rationalization. Ann Clin Biochem 2012; 49:323-36. http://dx.doi.org/10.1258/acb. 2011.011149. 


\section{AUTHORSHIP AND CONTRIBUTION DECLARATION}

\begin{tabular}{|c|l|l|}
\hline Sr. \# & \multicolumn{1}{|c|}{ Author-s Full Name } & \multicolumn{1}{|c|}{ Contribution to the paper } \\
\hline 1 & Rehma Dar & Main idea and discussion. \\
\hline 2 & Nida lqbal & Article writing and editing. \\
\hline 3 & Ayesha Ashfaq & $\begin{array}{l}\text { Data collection and references } \\
\text { writing. }\end{array}$
\end{tabular}

